\title{
Predicting the Emissions Characteristics of Charcoal Fired Cook stoves from their Thermal Performance Indicators
}

\author{
William Owusu Oduro \\ Patience Mamle Agbedor \\ Gloria Boafo-Mensah \\ Kofi Ampomah-Benefo \\ Maame Adwoa Bentumah Animpong \\ Elizabeth Von-Kiti \\ Ebenezer Neequaye Kotey \\ Gabriel Nii Laryea \\ Kisiedu Akufo-Kumi \\ Council for Scientific and Industrial Research \\ Institute of Industrial Research \\ Ghana, P. O. Box LG 576 Legon
}

\begin{abstract}
This paper presents basic statistical model to predict emissions factors of $\mathrm{CO}, \mathrm{CO}_{2}$ and $\mathrm{PM}_{2.5}$ from the thermal performance (firepower) using results from an experimental Water Boiling Test with Laboratory Emissions Monitoring System of twelve (12) different traditional and improved charcoal fired cookstoves. The development of improved biomass cookstoves with superior thermal performance and emission characteristics thus has huge environmental and social benefits because of the risks associated with inefficient stoves. A statistical Pearson correlation coefficient (r) was used to determine the degree of linear association of the combustion characteristics with the emissions factors. The models for the evaluation of cookstove emissions from the firepower of a charcoal fired cookstove proved reasonably accurate for the prediction of $\mathrm{CO}_{2}, \mathrm{CO}$ and $\mathrm{PM}_{2.5}$ without direct measurement using laboratory emissions monitoring systems.
\end{abstract}

Keywords: Statistical model, Cookstove emissions, Thermal performance indicators

\subsection{Introduction}

Biomass is a renewable source of energy with net zero addition to the carbon cycle because it absorbs carbon dioxide during growth and releases it in combustion. Bioenergy provides approximately 11\% (44.3 EJ) of the world's total primary energy supply with almost two thirds of it consumed in developing countries. Its utility is limited to low and medium temperature process heat and remains the largest source of renewable energy in the world, underpinning its importance in the energy economy (IEA, 2017). Woodfuel is the primary source offuel for cooking in many developing countries because of its easy accessibility and affordability (Demirbas, 2004). Charcoal or torrefied biomass is considered a cleaner biomass energy feedstock with improved energy content or heating value because the torrefaction process reduces the moisture content and $\mathrm{O}_{2}$ levels as well asdevolatizes the biomass thereby increasing the energy density (Mamvura \& Muzenda, 2015). However, the consequent effect of heavy dependence on wood fuel using inefficient cookstoves leads to deforestation and emission of harmful gases (smoke pollution) in the kitchen environment with negative health impact. Improved charcoal-burning stoves offer significant reductions in indoor air pollution compared to the stoves that use fuelwood (Ezzati, Mbinda, \& Kammen, 2000).

The development of improved biomass cookstoves with superior thermal efficiency and emission characteristics is therefore an important renewable energy technology with far reaching environmental benefits both locally and globally. Testing cookstoves thus encompasses two major aspects; thermal performance indicators (thermal efficiency, specific fuel consumption, burning rate, firepower) as well as emission characteristics $\left(\mathrm{CO}_{2}, \mathrm{CO}\right.$ and Particulate Matter $<2.5$ microns) at both high and low power output. Emission factors measure the mass of pollutant emitted per unit mass of fuel consumed ( $\mathrm{g} / \mathrm{kg}$ of fuel) by a particular stove. 
Hence it is an effective tool for comparing the cleanliness of different stoves performing similar functions (Bhattacharya, Albina, \& Abdul Salam, 2002).Emission factors from domestic cookstoves for a given fuel type are affected by stove design (and by extension fire management and ventilation influenced by air supply amount and fuelair mixing condition)(Makonese, Masekameni, Annegarn, \& Forbes, 2017).Testing the emission levels of improved biomass cookstoves require state-of the art precision equipment which comes at huge cost to developers of these stoves. Mathematical or statistical modeling can be used to translate problems from an application area into tractable mathematical formulations whose theoretical and numerical analysis provides guidance for useful real-time applications (Neumaier, 2004).

This paper presents basic algorithm toolkits (numerical statistics) to predict parameter (emissions factors of $\mathrm{CO}, \mathrm{CO}_{2}$ and $\mathrm{PM}_{2.5}$ ) estimation from the thermal performance (firepower) of charcoal fired cookstoves using results from an experimental study of twelve (12) different traditional and improved charcoal fired cookstoves tested by the Regional Testing and Knowledge Centre in Ghana. The aim is to develop a statistical model to predict fairly the emission factor of $\mathrm{CO}, \mathrm{CO}_{2}$ and fine particulate matter $\left(\mathrm{PM}_{2.5}\right)$ using data from the thermal performance indicators of the stove which influences the combustion characteristics and heat delivery of the stove to a cooking pot placed on it. These thermal performance indicators are more easily computed without extensive experimentation. The statistical model tool kit will help cookstove developers to do a quick screening to assess how design parameters influence emissions.

\subsection{Materials and Methods}

\subsection{Materials}

Twelve (12) charcoal fired domestic cookstoves of varying design and size available on the Ghanaian market were tested. Charcoal from neem (Azadirachtaindica) was purchased from a local producer in Ghana and stored in a cool dry laboratory environment in paper bags. The Lower Heating Value was $(29300 \mathrm{~kJ} / \mathrm{kg})$ and average moisture content \pm standard deviation was determined to be $9.3 \pm 1.7 \%$. Hence the corrected net caloric value of the charcoal was 26575 $\mathrm{kJ} / \mathrm{kg}$.

\subsection{Methods}

\subsubsection{Stove Testing Protocol WBT Version}

The Water Boiling Test (WBT version 4.2.3) was conducted to determine the performance of the stoves. Three phases i.e.a cold-start phase, hot-start phase, and a simmering phase were tested. All the cookstoves are lighted by the Top Lit Up Draft (TLUD) method (Makonese, Masekameni, Annegarn, \& Forbes, 2017). The cold-start phase test begins with the stove at room temperature and boils $5 \mathrm{~L}$ of water in a $7 \mathrm{~L}$ pot without a lid, placed in a hood with an extractor. In the hot-start phase, water is boiled beginning with a hot stove to identify differences in performance between a hot and cold stove body. During the simmering phase the remaining water in the hot-start phase is kept at approximately $3^{\circ} \mathrm{C}$ below boiling for $45 \mathrm{~min}$. Each stove's $\mathrm{CO}$ and $\mathrm{CO}_{2}$ emissions data were measured using Aprovecho Research Centre's Emissions Measurement Sensor Box. A cyclone with a filter (2.5 microns) was used to determine the fine particulate matter $(\mathrm{PM}>2.5 \mu)$ by gravimetric analysis whilst fine particulate matter $(\mathrm{PM}<2.5)$ data were collected using the sensor box from Aprovecho Research Center.

Each stove type was tested in triplicates (following the standard WBT version 4.2.3 in a controlled laboratory setting) and the average of each parameter (firepower and emissions factors of $\mathrm{CO}_{2}, \mathrm{CO}$ and $\mathrm{PM}_{2.5}$ ) calculated. The air (ambient) temperature was $27-30^{\circ} \mathrm{C}$, the local boiling point was $100^{\circ} \mathrm{C}$, and the relative humidity was $70 \%$.

\subsubsection{Firepower}

The firepower (W) of a stove is the energy released by the burning fuel at unit time. It defines the capacity of the cookstove to deliver effective heat to the cooking pot and was calculated from Equation 1

Firepower $(W)=\frac{\left(m_{f i}-m_{f c}\right) \times H_{c}}{t}$

where $m_{f i}$ the initial mass of fuel in the cookstove $(\mathrm{g}), m_{f c}$ the final mass of fuel after bring 51 of water to boil $\left(100^{\circ} \mathrm{C}\right)$, $H_{c}$ energy content of fuel (J/g) for charcoal was taken to be $26575 \mathrm{~kJ} / \mathrm{kg}$ (factoring a moisture content of $9.3 \%$ ) and $t$ time (s) it took to raise the temperature of the water from ambient $\left(27^{\circ} \mathrm{C}\right)$ to boiling point $\left(100{ }^{\circ} \mathrm{C}\right)$. The firepower of a stove therefore, given a good heat retention design to minimize losses to the environment, can influence the Thermal Efficiency which is defined as the ratio of the energy entering the pot to the energy content of the fuel consumed.

(Bhattacharya, Albina, \& Abdul Salam, 2002). 


\subsubsection{Emission factor}

The standard measure of emission from the combustion systems is the emission factor which is simply the mass of the pollutant emitted per unit mass of the fuel consumed $\left(\mathrm{g} \mathrm{kg}^{-1}\right.$ of fuel). This was determined from the Laboratory Emissions Monitoring System (LEMS) hood in a chamber.

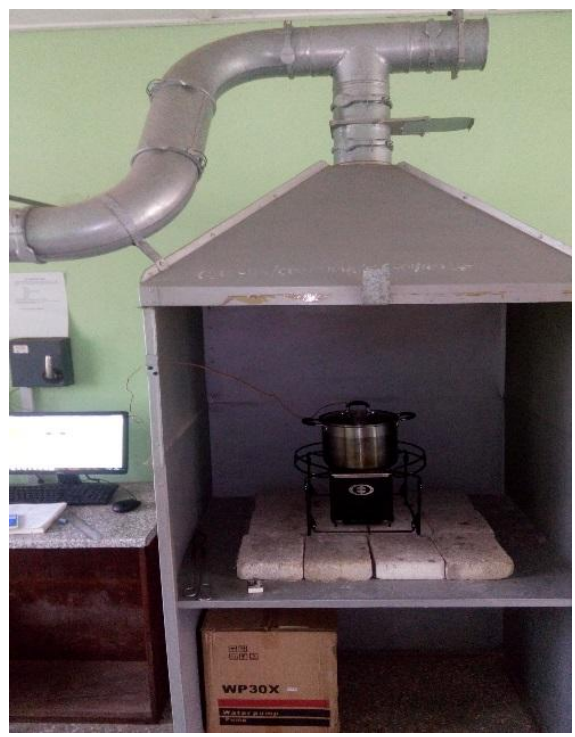

Figure 1. A Laboratory Emissions Monitoring System set-up used for the Water Boiling Test of the different stoves showing the extractor hood

\subsubsection{Statistical tools}

A Microsoft Excel spreadsheet was used to analyze the data. The Pearson correlation coefficient (r) was used to determine the degree of linear association of the combustion characteristics with the emission factors. For absolute values of $\mathrm{r}, 1.0-0.8$ indicates very strongly associated, 0.79-0.6 depicts strongly associated, 0.59-0.4 shows moderately associated, 0.39-0.2 is weak association and $0-0.19$ represents very weak association. The Standard Error of $\mathrm{r}, \mathrm{SE}(\mathrm{r})$, for $\mathrm{n}-2$ degrees of freedom given by the Equation (5), was used to estimate the extent of deviation of the predicted emission factor from experimentally determined factor. The Standard Error provided information on the accuracy of the statistic as a measure of the dispersion (or variability) of the predicted scores in a regression.

$S E(r)=\sqrt{\frac{1-r^{2}}{n-2}}---(2)$,

The significance of the association was determined using a Students' t-test under the null hypothesis with n-2 degrees of freedom given by the Equation (3) and the stat $t$ observed compared with stat $t$ from table.

$t=\frac{r}{S E(r)}---(3)$.

The percentage error (\%) was computed using Equation (4).

PercentageError $(\%)=100 \times \frac{S . E}{r}---(4)$

\subsection{Results and Discussions}

3.1 Predicting $\mathrm{CO}_{2}$ emissions from Combustion characteristics of stoves 


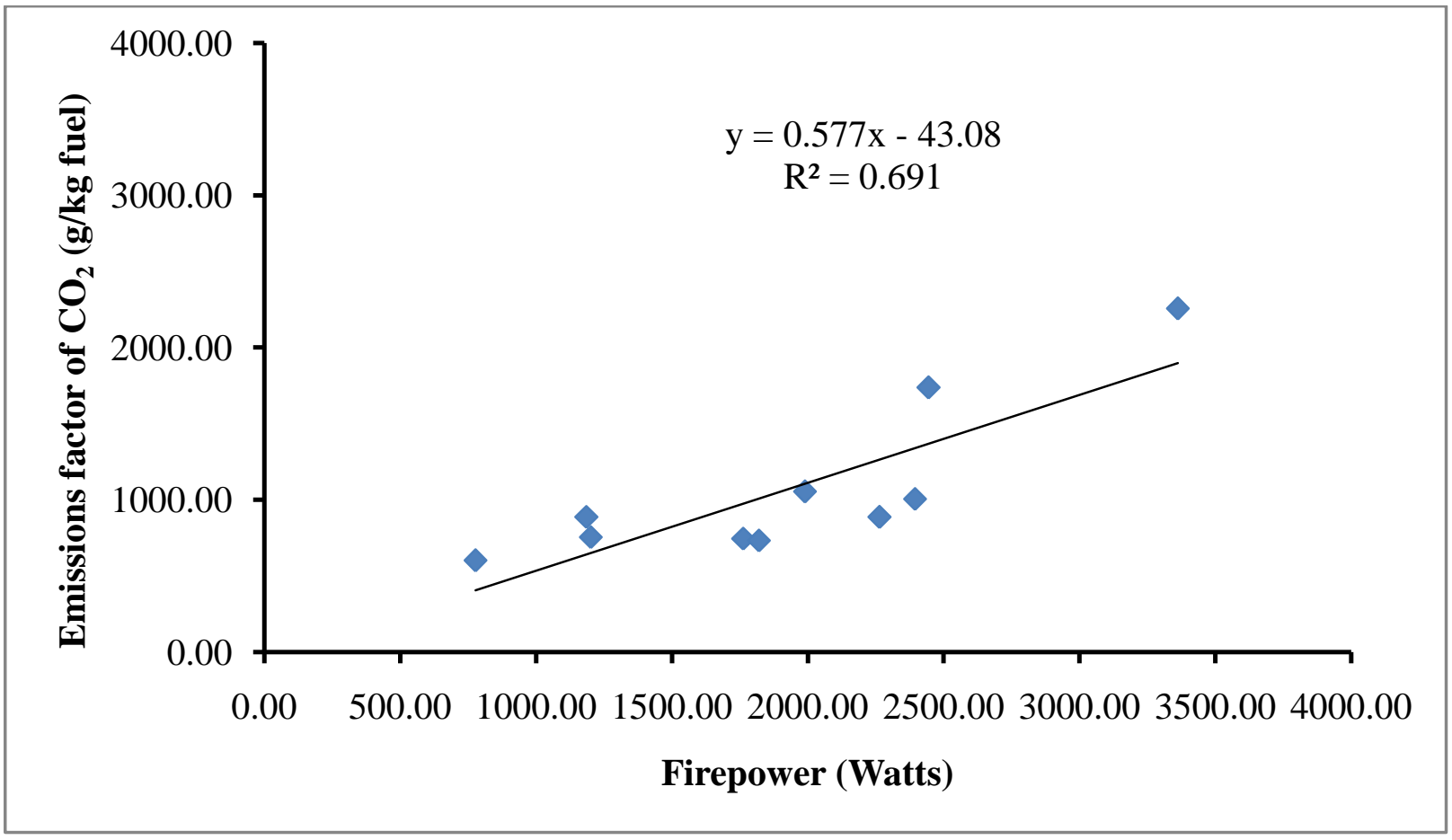

Figure 2. A scatter plot of Firepower (Watts) and the emission factor of $\mathrm{CO}_{\mathbf{2}}$ (g/kg of fuel)

The emission factor of $\mathrm{CO}_{2}$ is accurately predicted by Firepower (Watts) of the charcoal fired cookstoves with a very strong positive correlation $(\mathrm{n}=12$ and $\mathrm{P}<0.001)$ as shown in Fig. 2 and Table 1. Thus, $\mathrm{CO}_{2}$ emission factor increases as the firepower of the stove increases and the modely $=0.5775 x-43.08$, predicts with $83 \%$ of variability in the $\mathrm{CO}_{2}$ emission factor is explained by the linear relationship between $\mathrm{CO}_{2}$ emission factor and Firepower of the stove. A Standard Error of 0.18 indicates that the experimental values cluster closer to the predicted values from the regression line and about $99.9 \%$ of the experimental values fall within $\pm 21 \%$ (Percentage Error) of the Pearson correlation coefficient indicating the association of the variables.

Table 1 Trend analysis of the association of emission factor of $\mathrm{CO}_{2}, \mathrm{CO}$ and $\mathrm{PM}_{<2.5}$ with the Firepower of a charcoal stove

\begin{tabular}{|l|c|c|l|l|l|l|}
\hline Emission & $\begin{array}{c}\text { Prediction } \\
\text { Model }\end{array}$ & $\mathbf{R}^{2}$ & $\begin{array}{c}\text { Correlation } \\
\text { coefficient }\end{array}$ & $\begin{array}{c}\text { Degree of } \\
\text { Association }\end{array}$ & $\begin{array}{c}\text { Standard } \\
\text { Error }\end{array}$ & Significance level \\
\hline $\mathrm{CO}_{2}$ & $\begin{array}{l}y \\
=0.5775 x \\
-43.08\end{array}$ & 0.6912 & 0.8314 & Very strong Positive & 0.1757 & $\mathrm{P}<0.001$ \\
\hline $\mathrm{CO}$ & $y=0.0251 x$ & 0.6349 & 0.7968 & Positive moderate & 0.1911 & $\mathrm{P}<0.1$ significant \\
\hline $\mathrm{PM}$ & $y$ & 0.7453 & 0.8633 & Very strong positive & 0.1596 & $\begin{array}{l}\mathrm{P}<0.001 \text { positive } \\
\text { association } \\
\text { significant }\end{array}$ \\
\hline
\end{tabular}




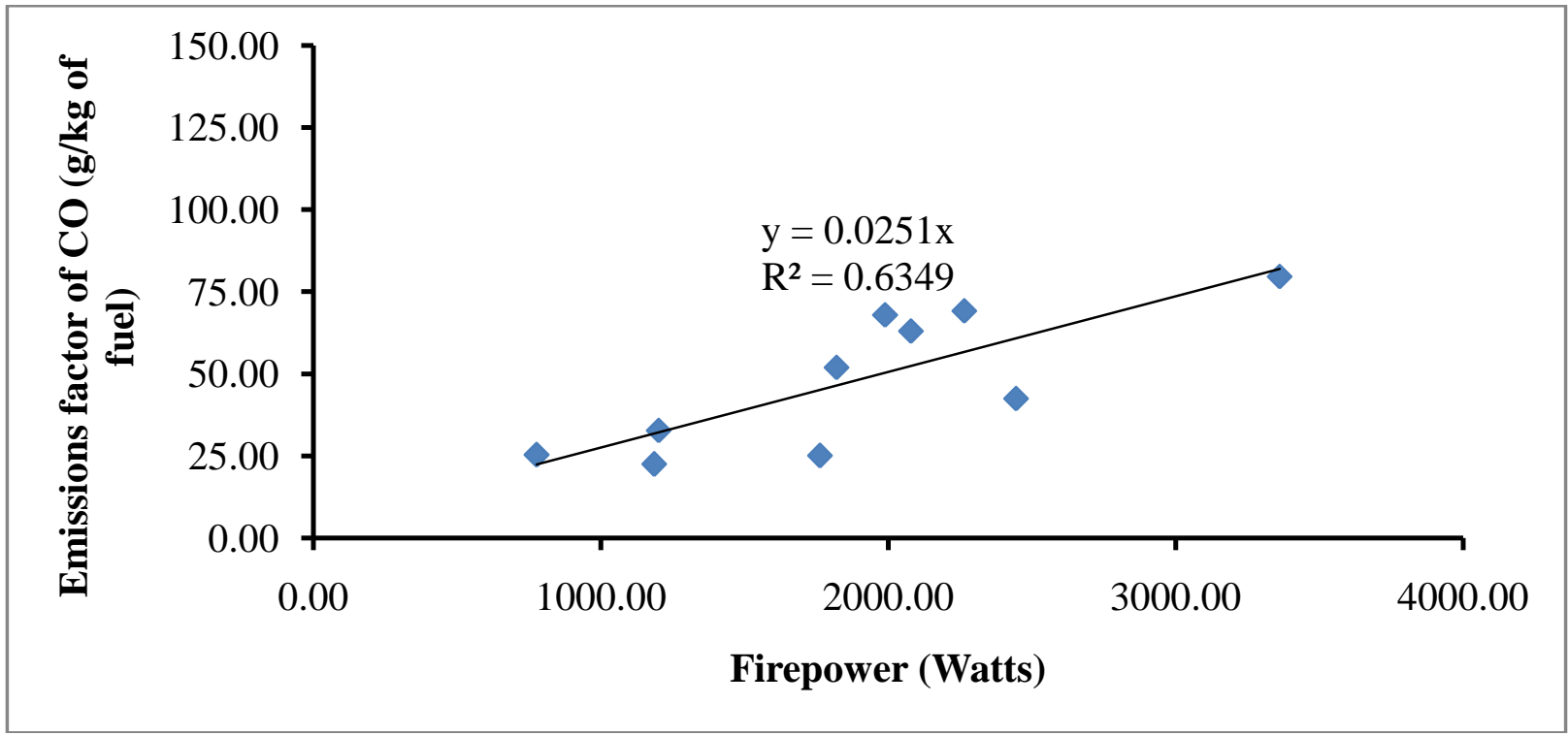

Figure 3 A scatter plot of Firepower (Watts) and the emission factor of $\mathrm{CO}$ (g/ $/ \mathrm{kg}$ of fuel).

Carbon monoxide is a very toxic colorless, odorless gas with a propensity to bind to the blood hemoglobin leading to oxygen starvation to the cells leading to death. Assessing the quantities emitted by a cookstove technology used in a kitchen environment is therefore of high importance and of huge health consequences.Analysis of the statistical data on $\mathrm{CO}$ emission factor for the twelve different stoves at various stages, cold start, hot start and simmering, indicate that firepower positively correlated to the $\mathrm{CO}$ emission factor with moderate association.Thus, $\mathrm{CO}$ emission factor increases as the firepower increases. The model, $y=0.0251 x$ predicts with an $80 \%$ of variability in the $\mathrm{CO}$ emission factor explained by thelinear relationship between the emission factor of $\mathrm{CO}$ and the Firepower of the charcoal stoves. Predicting $\mathrm{CO}$ emissions factor by Firepower $(\mathrm{n}=12$ and $\mathrm{P}<0.1)$ by the model gives a Standard Error of 0.19 which indicates that the experimental values cluster closer to the predicted values from the regression line and about $90 \%$ of the experimental values fall within $\pm 12 \%$ (Percentage Error) as shown in Fig. 3 and Table 1. Flames burn hotter in the presence of more oxygen. Burning with excess oxygen also reduces the emissions associated with incomplete combustion like CO. Hence a negative association of Firepower to $\mathrm{CO}$ was expected. However, moderately positive association was observed due to the non-stoichiometric amounts of oxygen intake from the natural draft stoves.

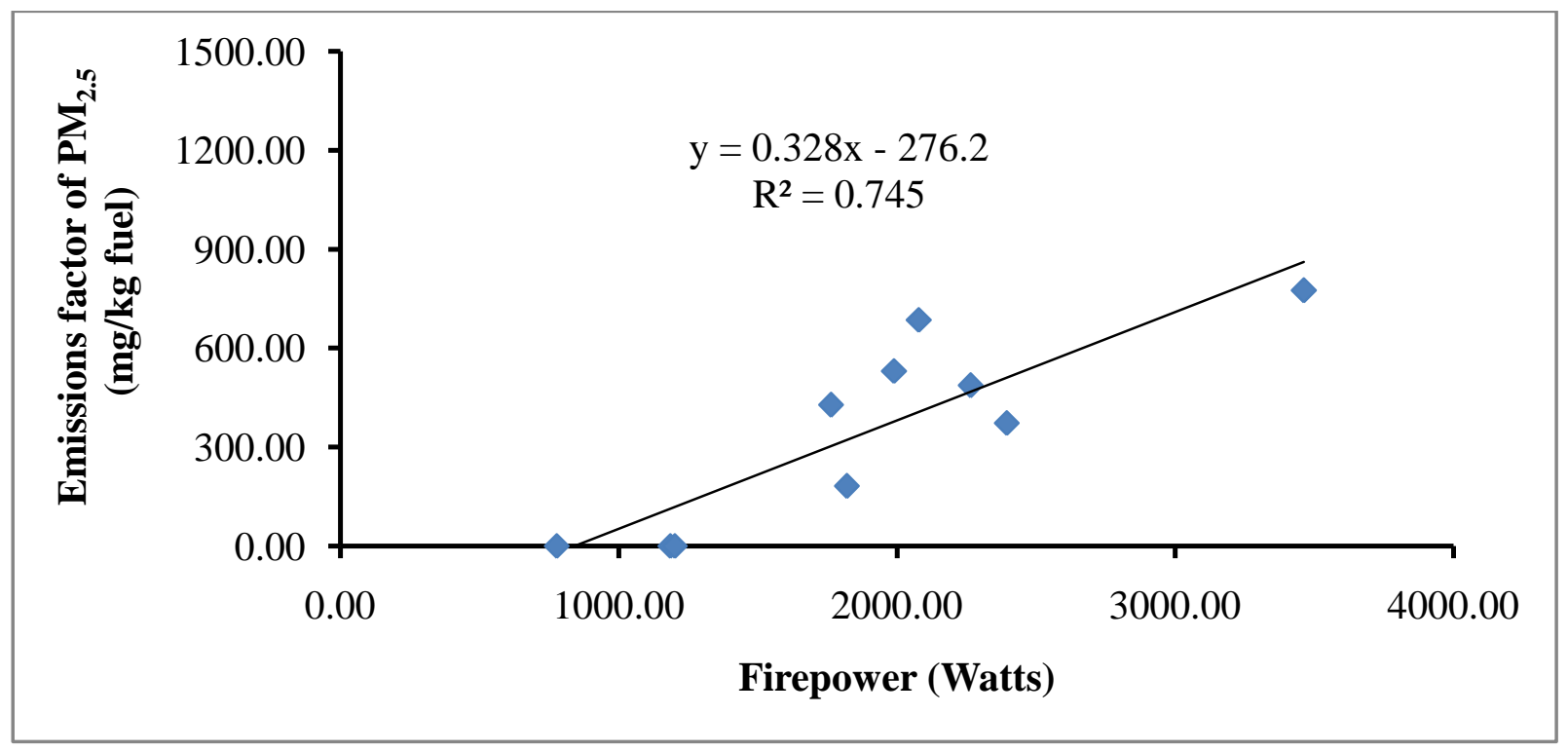

Figure 4 A scatter plot of Firepower (Watts) and the emission factor of Particulate Matter $\mathrm{PM}_{<2.5}(\mathrm{~g} / \mathrm{kg}$ fuel). 
The particulate matter is one of the ubiquitous emission concerns in solid fuel cookstoves use. Personal exposure to $\mathrm{PM}_{<2.5}$ has been related to the occurrence of pulmonary diseases associated with the cooking environment. There have been strict regulations on the monitoring of $\mathrm{PM}_{2.5}$. Therefore, a statistical tool that accurately predicts the emissions of particulate matter would be a handy tool to the design and construction of cookstoves in monitoring the emissions of $\mathrm{PM}_{<2.5}$ from improved designs and by extension the personal exposure of particulate matter in the form of soot (carbon), Polycyclic Aromatic Hydrocarbons (PAHs) etc. during cooking to ensure better performance prior to sending to designated testing centres for confirmatory tests.

The model, $y=0.3288 x-276.29$ predicts with $86 \%$ of variability in the PM emission factor explained by the linear relationship between the emission factor of PM and the Firepower of the charcoal stoves. Predicting PM emissions factor by Firepower $(\mathrm{n}=12$ and $\mathrm{P}<0.001)$ by the model gives a Standard Error of 0.16 which indicates that the experimental values cluster closer to the predicted values from the regression line and about $99.9 \%$ of the experimental values fall within $\pm 18 \%$ (Percentage Error) as shown in Fig.4 and Table 1 .

Higher firepower of stoves and fireplaces have been reported in the literature to produce more particulate matter per $\mathrm{kg}$ of fuelwood (Fernandes, et al., 2011). In charcoal (torrefied wood), the oxygen content is low and has a higher energy density and the stove designs with natural draft systems usually do not have sufficient air flow to enable the attainment of stoichiometric ratios of air and fuel for lean, cleaner burning as air flow has been shown in the literature to reduce PM emissions in particularly high firepower chimney stoves by over 90\% (Hogberg, 2017).

\section{Validation of Model}

To test the accuracy of the model for predicting emission factor of $\mathrm{CO}$ and $\mathrm{PM}_{2.5}$ from the firepower, different domestic charcoal stove designs independently tested at various laboratories in the literature (Obeng, Mensah, Ashiagbor, Boahen, \& Sweeney, 2017) (Lask, et al.), were calibrated to the model and the deviation of the experimentally determined emission factor from the projected emission factor was calculated (Table 2). The results show the deviation between the theoretically derived and the experimentally determined emission factor of $\mathrm{CO}$ was small indicating more precision (average percentage error, 27\%) compared with predicting the $\mathrm{PM}_{2.5}$ (average percentage error, 116\%). Thus, the model for predicting $\mathrm{CO}$ emission factor from the firepower of the stove will have a lower uncertainty than predicting the particulate matter. This could be because particulate matter is highly influenced by the type and state of the fuel which is susceptible to variability (the type of wood from which the charcoal was produced) whilst the CO is influenced by the air fuel mix in the combustion process which is more of a property of the stove design.

Table 2 A comparison of the experimentally determined emissions factor with the theoretically predicted emissions factor from the Statistical models

\begin{tabular}{|c|c|c|c|c|c|c|c|c|c|}
\hline Thermal Performance & \multicolumn{3}{|c|}{ Gyapa charcoal stove $^{a}$} & \multicolumn{3}{|c|}{ Traditional Charcoal stove } & \multicolumn{3}{|c|}{ Ghana Coal Pot $^{\text {a }}$} \\
\hline Firepower $(\mathrm{W})$ & \multicolumn{3}{|c|}{4802.7} & \multicolumn{3}{|c|}{4250} & \multicolumn{3}{|c|}{6066} \\
\hline \multirow[t]{2}{*}{ Emission Performance } & \multirow{2}{*}{$\begin{array}{l}\text { Expt. } \\
\text { value }\end{array}$} & \multicolumn{2}{|c|}{ Predicted value } & \multirow{2}{*}{$\begin{array}{l}\text { Expt. } \\
\text { value }\end{array}$} & \multicolumn{2}{|c|}{ Predicted value } & \multirow{2}{*}{$\begin{array}{l}\text { Expt. } \\
\text { Value }\end{array}$} & \multicolumn{2}{|c|}{ Predicted value } \\
\hline & & FP & $\%$ Error & & FP & $\%$ Error & & FP & $\%$ Error \\
\hline $\mathrm{CO}(\mathrm{g} / \mathrm{kg})$ & 104.8 & 98.8 & 43 & 79 & 55.24 & 6 & 116.44 & 152.26 & 31 \\
\hline $\mathrm{PM}_{2.5}(\mathrm{~g} / \mathrm{kg})$ & 5.06 & 1.3 & 74 & 1.04 & 1.12 & 8 & 0.47 & 1.72 & 266 \\
\hline
\end{tabular}

NB. ${ }^{a}$ (Obeng, Mensah, Ashiagbor, Boahen, \& Sweeney, 2017), and ${ }^{\mathrm{c}}$ (Coffey, et al., 2017).

\section{Conclusions}

The models for the evaluation of cookstove emissions factors from a thermal performance indicator, firepower, of a charcoal fired cookstove proved reasonably accurate for the prediction of $\mathrm{CO}_{2}, \mathrm{CO}$ and $\mathrm{PM}_{2.5}$ without direct measurement using laboratory emissions monitoring systems. Though the direct prediction of $\mathrm{CO}$ and $\mathrm{PM}_{2.5}$ can very fairly be predicted by the firepower, the certainty in predicting the $\mathrm{CO}$ emission factor with the statistical model was significantly higher than predicting PM because of the intrinsic effect of fuel quality in PM emissions in cookstoves as compared to $\mathrm{CO}$.

\section{References}

Bhattacharya, S. C., Albina, D. O., \& Abdul Salam, P. (2002). Emission factors of wood and charcoal-fired cookstoves. Biomass and Bioenergy , 23, 453 - 469. 
Coffey, E. R., Muvandimwe, D., Hagar, Y., Wiedinmyer, C., Kanyomse, E., Piedrahita, R., . . . Hannigan, M. P. (2017). New Emission Factors and Efficiencies from in-Field Measurements of Traditional and Improved Cookstoves and Their Potential Implications. Environmental Science \& Technology, 51(21), 12508-12517.

Demirbas, A. (2004). Combustion characteristics of different biomass fuels. Progress in Energy and Combustion Science, 30(2), 219-230.

Ezzati, M., Mbinda, B. M., \& Kammen, D. M. (2000). Comparison of emissions and residential exposure from traditional and improved cookstoves in Kenya. Environmental Science Technology, 34(4), 578-583.

Fernandes, A. P., Alves, C. A., Goncalves, C., Tarelho, L., Pio, C., Schimdl, C., \& Bauer, H. (2011). Emission factors from residential combustion appliances burning Portuguese biomass fuels. Journal of Envirnmental Monitoring, 11(3), 196-206.

Hogberg, T. (2017). The effect of ambient air-injection on particulate matter emissions in high firepower chimney cookstoves. Colorado State University, Department of Mechanical Engineering. MSc. Thesis.

IEA. (2017, September 18). Renewables, Bioenergy and Biofuels: International Energy Agency. Retrieved November 8, 2017, from International Energy Agency Web site: https://www.iea.org/topics/renewables/bioenergy/

Lask, K., Booker, K., Han, T., Granderson, J., Yang, N., Ceballos, C., \& Gadgil, A. (n.d.). Performance comparison of charcoal cookstoves for Haiti: Laboratory Testing with water boiling and controlled cooking tests. Energy for Sustainable Development, 26, 79-86.

Makonese, T., Masekameni, D. M., Annegarn, H. J., \& Forbes, P. B. (2017). Emission factors of domestic coal-burning braziers. South African Journal of Science, 113(3/4), 1-11.

Mamvura, T., \& Muzenda, E. (2015). Effect of blending coal with torrefied biomass for possible application in energy production. South African Journal of Chemical Engineering, 20(2), 18-30.

Neumaier, A. (2004). Chapter 3, Mathematical model building. In J. Kallrath (Ed.), Applied Optimization: Modeling languages in mathematical optimization (Vol. 88). Boston: Kluwer.

Obeng, G. Y., Mensah, E., Ashiagbor, G., Boahen, O., \& Sweeney, D. J. (2017). Watching the smoke rise up: Thermal efficiency, pollutant emissions and global warming impact of three biomass cookstoves in Ghana. Energies, 10,641 . 